\title{
COMPARATIVE EVALUATION OF THE CLINICAL, LABORATORY AND TREATMENT PROFILE OF PSORIATIC ARTHRITIS AMONG MEN AND WOMEN IN AN OUTPATIENT SERVICE
}

\author{
Rebeca Loureiro Rebouças ${ }^{1, \star}$, Arthur Rodrigues Caetano De Sousa ${ }^{1}$, Naiara Bozza Pegoraro ${ }^{1}$, Thelma Larocca Skare ${ }^{1}$ \\ 1.Faculdade Evangélica Mackenzie do Paraná, Curitiba (PR), Brazil. \\ *Corresponding author: rebecareboucas@gmail.com
}

\section{BACKGROUND}

Psoriatic arthritis (PSA) is an autoimmune inflammatory arthritis associated with cutaneous psoriasis. On average, $5 \%$ to $10 \%$ of patients with cutaneous psoriasis will develop PsA. Hormonal factors and sex chromosomes were identified as possible pathogenic factors inducing a sexual dimorphism in the immune system, and modifying the disease presentation and response to the therapeutic approach. Therefore, the objective of this study was to characterize patients with PsA regarding the epidemiological, clinical, laboratory and therapeutic aspects as well as articular form of presentation and compare them according to gender.

\section{METHODS}

This is an observational cross-sectional retrospective study using medical records as the data source. Epidemiological data, disease subtype, laboratory profile, extra-articular clinical manifestations and medication history were collected. Patients who met the 2006 Classification Criteria for Psoriatic Arthritis (CASPAR) for PsA were included and those under 18 years old and with overlaps with other rheumatologic diseases were excluded.

\section{RESULTS}

One hundred and five patients with PsA were found, $53.33 \%$ men, with a median age at diagnosis of 55 years and with disease duration of 7 years. The most common extra-articular clinical findings were nail involvement in $28.57 \%$, dactylitis in $35.24 \%$, enthesitis in $30.48 \%$ and sacroiliitis in $17.14 \%$. The main used medication was methotrexate in $57.14 \%$, followed by adalimumab in $13.33 \%$ and prednisolone in $11.43 \%$. Men smoked more than women $(p=0.025)$. Comparing men and women regarding extra-articular manifestations and used medications, only nail involvement was different $(p=0.03)$ being more common in men. No other statistically relevant differences were found including on articular forms subtypes ( $p=n s)$.

\section{CONCLUSION}

The population with PsA found was predominantly male, middle-aged, with less than a decade of the disease. The main extraarticular manifestation found was dactylitis and the most used medication was methotrexate. Men had more nail involvement and used more tobacco when compared to women.

\section{KEYWORDS}

Autoimmunity, Arthritis, Psoriatic, Antirheumatic agents. 